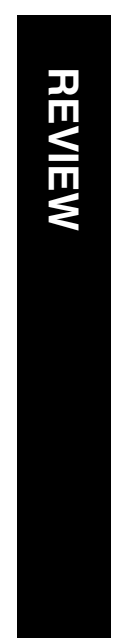

\section{Vital staining with indocyanine green: a review of the clinical and experimental studies relating to safety}

${ }^{1}$ Department of Ophthalmology, King's College Hospital, London, UK

${ }^{2}$ Department of Ophthalmology, Rayne Institute, King's College London, London, UK

Correspondence:

TL Jackson,

Department of

Ophthalmology, King's College Hospital, London SE5 9RS, UK Tel: + 44203299 3385; Fax: + 442032993738 . E-mail: Gillian.Williams@ kch.nhs.uk

Received: 17 March 2008 Accepted in revised form: 27 June 2008

Published online: 1 August 2008

Conflict of interest: None.

\begin{abstract}
Indocyanine green (ICG) is extremely effective when used as a vital stain during macular hole surgery. By staining the internal limiting membrane, ICG facilitates removal of this delicate and sometimes hard to visualize structure. There is, however, considerable debate regarding its safety. This review considers the clinical and experimental studies of ICG and a related agent, infracyanine green. Some clinical papers show visual field defects, reduced visual acuity, and persistence of ICG at the macula and optic nerve. Other clinical studies fail to demonstrate toxicity. The experimental studies are also conflicting, but there are emerging trends. These suggest that surgeons who continue to use ICG should use concentrations not greater than $0.05 \mathrm{mg} / \mathrm{ml}$, in fluid-filled eyes, with short exposure times, iso-osmolar solutions, and avoid proximal or prolonged endoillumination of stained tissue. A smaller number of studies suggest that infracyanine green produces similar staining to ICG, and may possibly be safer, but there are too few well-designed studies to reach a conclusion. Although the use of ICG continues, on the balance of evidence, this review suggests that it is has the potential to produce subtle visual damage.
\end{abstract}

Eye (2009) 23, 504-518; doi:10.1038/eye.2008.249; published online 1 August 2008

Keywords: indocyanine green; infracyanine green; toxicity; review; safety; macular hole

\section{Introduction}

Indocyanine green (ICG) is a tricarbocyanine dye $\left(\mathrm{C}_{43} \mathrm{H}_{47} \mathrm{~N}_{2} \mathrm{O}_{6} \mathrm{~S}_{2} \mathrm{Na}\right)$ that binds avidly to serum proteins, with peak absorption in the infrared spectrum $(800 \mathrm{~nm})$. The latter property underlies its application as a fluorophore in choroidal angiography. ICG can also acts as an effective chromophore, staining the internal limiting membrane (ILM) of the retina green. By staining the ILM, ICG can help surgeons dissect this hard-to-visualise structure from the underlying retina during pars plana vitrectomy.

Initial enthusiasm for ICG as a vital stain was followed by reports showing possible toxicity, and a sometimes vociferous debate ensued regarding the safety, or otherwise, of ICG. Some clinicians have reported favourable surgical results using ICG, others identified adverse effects including reduced visual acuity (VA), optic disc changes, and visual field defects. Experimental studies have also shown potential toxicity, but not all studies concur, particularly when using lower concentrations of ICG.

This review appraises the clinical and experimental literature on ICG safety. Firstly, it considers the clinical series in which ICG was used, and then studies indicating that ICG can persist in the eye for an extended period of time. Next is a section dealing with surgical techniques that may minimize the risk of toxicity. Following this is an appraisal of the in vivo animal experiments, organ culture, cell culture, and histological studies. Infracyanine green, a closely related agent, is also evaluated, considering both clinical and experimental studies. Finally this article attempts to distil the key issues and draw some conclusions on the safety of ICG.

\section{Materials and methods}

Clinical and experimental articles were identified using a Biomed Medline and 
EMBASE database search (1997-2007 inclusive) using the following keywords and Mesh headings: indocyanine green, ICG, infracyanine green, toxicity, safety, macular hole, and vitrectomy. Articles in English, French, and German were included, but those appearing only as abstracts were excluded. Further articles were identified from the reference list of each article, and following peer review. Because of the paucity of randomized clinical trials and varying investigative methods, statistical metaanalysis was not deemed appropriate. Instead, all papers were reviewed and emerging trends were identified, with selected articles referenced in this summary paper.

\section{Clinical studies}

\section{Background}

There have been a considerable number of clinical studies of ICG-assisted peeling of the ILM in the past few years, mostly in the context of macular hole surgery. Authors in favour of ICG-assisted ILM peeling provide multiple justifications for its use. ICG can undoubtedly improve visualization of the ILM, and it may shorten operating times and thereby also reduce endoillumination of the fovea. Improved visualization of the ILM may facilitate less traumatic removal and damage to the inner retina. There are, however, many reports of toxicity, with multiple adverse events reported in association with ICG use (see summary below) - the difficulty is establishing a causal link between the use of ICG and visual damage.

\footnotetext{
Summary: adverse events reported in association with ICG use

1 Reduced VA

2 Visual field defects

3 Retinal pigment epithelium changes

4 Reduced rate of macular hole closure

5 Persistence of ICG in the retina and optic nerve

6 Optic atrophy

7 Altered surgical cleavage plane with ILM peeling
}

low number of patients (19 in each group), and the concern therefore that it might not have been adequately powered to detect a subtle difference in VA.

Hillenkamp et $a l^{1}$ undertook a randomized clinical trial of 60 patients undergoing vitrectomy and epiretinal membrane peel, comparing the outcome with and without ICG. Surgery was combined with cataract surgery and $1 \mathrm{mg} / \mathrm{ml}$ ICG was dissolved in glucose to avoid hypo-osmolarity. Comparing both groups, there was no statistically significant difference in final VA, reduction in macular oedema using optical coherence tomography, or postoperative Amsler grid testing. The incidence of residual of recurrent epiretinal membrane was also similar but two patients in the ICG group were found to have visual field defects (a non-significant difference). On the basis of these findings, it was concluded that ICG did not produce manifest toxicity.

Kwok et $a l^{2}$ compared visual outcome and macular hole closure rates at 1 year, between ICG-assisted ILM peeling and no ILM peeling, with a better outcome in the former group. As the surgical intervention (peel or no peel) also differed, this study cannot be used to conclude on the effect of ICG per se. It did, however, fail to show any evidence of toxicity. The same team ${ }^{3}$ also conducted a randomized clinical trial to determine the effective minimum concentration required to produce sufficient ILM staining. Among the three different concentrations studied $(0.25,0.5$, and $1.25 \mathrm{mg} / \mathrm{ml})$, the $1.25 \mathrm{mg} / \mathrm{ml}$ concentration produced the best ILM staining. The operating time was equivalent in the three groups and no toxicity was observed clinically or angiographically in any group.

\footnotetext{
Summary: randomized clinical trials

1 Two trials directly assessed the effect of ICG staining on visual outcome

2 One trial showed a significant increase in central visual field defects with ICG

3 Neither showed a deleterious effect on VA
}

\section{Randomized clinical trials}

Beutel et $a l^{1}$ compared ILM peeling with trypan blue, an alternative vital stain, or ICG in macular hole surgery. The ICG concentration was $0.05 \mathrm{mg} / \mathrm{ml}(0.005 \%)$, with the dye washed out immediately after its application. Final ETDRS VA improved by two lines in both groups, without a significant difference. Compared with the trypan blue group, the ICG group had a larger number of central scotomas, as measured by mircoperimetry. Macular hole closure rate was $84 \%$ and similar in both groups. The strengths of this study were the standardized examination of patients by a single examiner and a single surgeon. The weakness was the

\section{Non-randomized studies}

Despite a plethora of non-randomized studies, there is still no clear consensus on the clinical safety of ICG macular staining (Tables 1 and 2). The key questions are related to the effect of ICG on visual outcome and whether or not ICG causes visual field defects.

\section{Visual and anatomic outcome}

Studies showing adverse visual and anatomic outcome In a retrospective multicentre study of 1627 patients, the use of ICG was found to make macular hole closure significantly less likely (96 vs 92\%). ${ }^{21}$ Further, in the holes 
Table 1 Visual outcome in relation to ICG concentration and duration of exposure

\begin{tabular}{|c|c|c|c|c|}
\hline Authors & $\mathrm{N}$ (eyes) & Concentration $(\mathrm{mg} / \mathrm{ml})$ & Time (s) & $\geqslant 2$ lines improvement in VA (\%) \\
\hline Da Mata et $a l^{4}$ & 24 & 5 & $118-300$ & 96 \\
\hline Da Mata et $a l^{5}$ & 121 & 5 & 30 & 96 \\
\hline Kumar $e t a l^{6}$ & 18 & 5 & 120 & 50 \\
\hline Apostolopouos et al ${ }^{7}$ & 20 & 5 & 60 & 90 \\
\hline Lochead et $a l^{8}$ & 34 & 5 & 10 & 82 \\
\hline Sheidow et $a l^{9}$ & 35 & 4.2 & $120-300$ & 71 \\
\hline Wolf $e t a l^{10}$ & 37 & 2.5 & $0^{\mathrm{a}}$ & 62 \\
\hline Das et $a l^{11}$ & 25 & 2.5 & NS & 64 \\
\hline Lai and Williams ${ }^{12}$ & 59 & 1.25 & 20 & 73 \\
\hline Kadonosono et $a l^{13}$ & 13 & 0.6 & 30 & 85 \\
\hline Ando et $a l^{14}$ & 16 & 0.5 & 10 & 100 \\
\hline Kwok et $a l^{2}$ & 18 & $0.25-1.25$ & 30 & 67 \\
\hline Kwok et al ${ }^{15}$ & 9 & 0.25 & 30 & 78 \\
\hline
\end{tabular}

Abbreviations: ICG = indocyanine green; $\mathrm{NS}=$ not specified; $\mathrm{VA}=$ visual acuity.

Table includes non-randomized studies of macular hole surgery that specifically reported the number of eyes with a VA improving by two lines or greater (see also Figure 1).

${ }^{\text {a } I m m e d i a t e ~ w a s h o u t ~ a f t e r ~ i n t r o d u c t i o n ~ o f ~ t h e ~ d y e . ~}$

Table 2 Visual field testing in patients exposed to ICG during macular hole surgery (non-randomized studies)

\begin{tabular}{|c|c|c|c|c|c|c|}
\hline \multicolumn{4}{|c|}{ Adverse effects } & \multicolumn{3}{|c|}{ No adverse effects } \\
\hline Authors & $\mathrm{N}$ (eyes) & Concentration $(\mathrm{mg} / \mathrm{ml})$ & $V F$ defect $(\%)$ & Authors & $\mathrm{N}$ (eyes) & Concentration $(\mathrm{mg} / \mathrm{ml})$ \\
\hline Kanda et $a l^{16}$ & 4 & $5^{\mathrm{a}}$ & 25 & & & \\
\hline Kanda et $a l^{16}$ & 12 & $5^{\mathrm{b}}$ & 100 & Kanda et $a l^{16}$ & 6 & 2.5 \\
\hline Nagai et $a l^{17}$ & 35 & 5 & 20 & & & \\
\hline Tsuiki et $a l^{18}$ & 96 & 2.5 & 18 & & & \\
\hline Gass et $a l^{19}$ & 18 & 0.5 & 50 & Ando et $a l^{14}$ & 16 & 0.5 \\
\hline Haritoglou et $a l^{20}$ & 20 & 0.5 & 70 & & & \\
\hline
\end{tabular}

Abbreviations: $\mathrm{ICG}=$ indocyanine green; $\mathrm{VF}=$ visual field

ammediate washout of ICG.

${ }^{\mathrm{b}} \mathrm{A}$ 3-min exposure of ICG.

that did close, visual outcome was significantly worse if ICG was used: $67 \%$ of the no-ICG group obtained two logMAR lines of improvement compared with $56 \%$ in the ICG group. This study was designed to compare ILM peeling with no peeling, rather than to look for ICG toxicity. ICG use was not standardized, and the exposure time and ICG concentration were not recorded. In addition, its retrospective nature means that confounding is a possibility. Nonetheless, this large and well-conducted analysis presents important findings that raise concerns about the efficacy and safety of ICG.

Nagai et $a l^{17}$ compared ILM-stained vs non-stained ILM in a retrospective study involving 35 eyes (17 unstained and 18 stained). The ICG concentration was $0.5 \mathrm{mg} / \mathrm{ml}$ followed by immediate rinsing of the dye. They found RPE atrophy in six stained eyes vs two in the unstained group. Furthermore, retinoschisis (in three patients) and visual defects (in seven patients) were found only in the ICG group. ICG has a maximal absorption at $800 \mathrm{~nm}$, which overlaps with the emission spectrum of the most commonly used halogen light sources. It was speculated that this might be the reason for the posterior RPE atrophy. RPE changes were also described by Engelbrecht et $a l^{22}$ in macular hole surgery with $0.1 \mathrm{mg} / \mathrm{ml}$ ICG staining. It should be noted that RPE changes have been described in macular hole surgery without ILM removal, before the introduction of ICG as a vital stain. ${ }^{23}$

Studies showing favourable visual and anatomic outcome In direct contrast to studies showing toxicity, several studies comparing ILM peel with and without ICG have shown better visual and anatomic outcome with ICG, despite using a range of concentrations and exposure times. Ando et al ${ }^{14}$ revisited their findings of visual field loss and worse visual outcome with $5 \mathrm{mg} / \mathrm{ml}$ ICG by decreasing the dye concentration and exposure time. Surgeries were performed with the same technique and the same surgeon, the only change being reduced ICG concentration $(0.5 \mathrm{mg} / \mathrm{ml})$ and exposure times (less than $10 \mathrm{~s})$. The ILM could still be visualized after one or two 
intravitreal ICG injections, but there were no visual field defects and no RPE changes. Macular hole closure was achieved in $93.5 \%$ and mean visual outcome improved significantly to $12 / 20$. $^{14}$

Lochhead $^{8}$ compared ILM stained with $5 \mathrm{mg} / \mathrm{ml}$ and no dye and reported a higher rate of macular hole closure in the stained group (91.2 vs 73.5\%). This was associated with a significant difference in visual outcome: logMar acuity improved above baseline in 53\% of the no-ICG group, compared with $82 \%$ of the ICG group. In a recent study, Mavrofrides et $a^{24}$ did not report any toxicity in patients receiving $2.5 \mathrm{mg} / \mathrm{ml}$ ICG. The macular hole closure rate was $87 \%$ with ICG vs $83 \%$ without ICG. After a follow-up of 8 and 9 months, median best corrected VA was $20 / 70$ and 20/80 in the ICG and no-ICG groups, respectively. Da Mata et al ${ }^{5}$ reported excellent visual outcomes in a large series (121 eyes) of patients undergoing macular holes surgery using $5 \mathrm{mg} / \mathrm{ml}$, with follow-up averaging 2 years, and with no ICG toxicity detected.

When considering the retrospective studies that specifically reported the percentage of eyes improving by greater than two lines of VA, there was no clear relationship between the final visual outcome and concentration or duration of dye exposure (Table 1 and Figure 1).

\section{Visual field defects}

\section{Studies showing visual field defects}

A number of authors have reported visual field defects in patients undergoing ICG staining. ${ }^{25}$ Tsuiki et al ${ }^{18}$ found a significantly increased incidence of nasal and temporal defects in the left and right eye, respectively - the authors suggested that this was related to direct

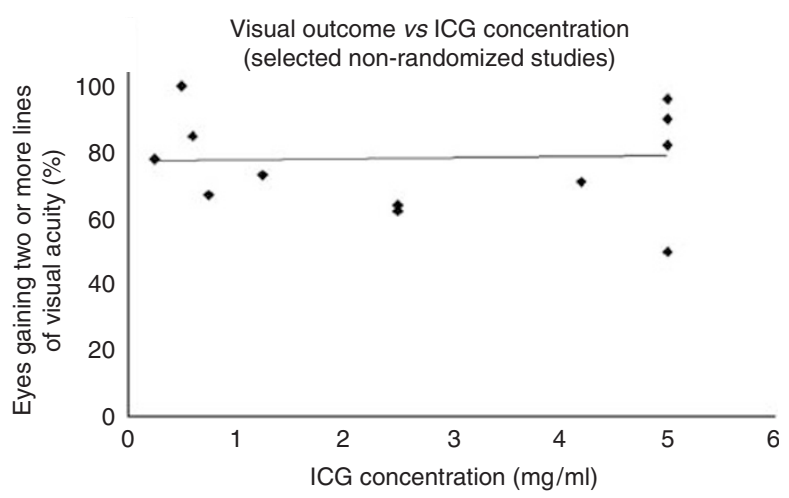

Figure 1 Compares visual acuity (VA) outcome in nonrandomized studies that detailed the percentage of eyes improving by two lines or greater (see also Table 1). A similar result was obtained when comparing VA and duration of dye exposure. illumination of ILM stained with $0.25 \mathrm{mg} / \mathrm{ml}$ ILM. Visual field defects could not be found when using an ICG concentration of $0.125 \mathrm{mg} / \mathrm{ml}$. Kanda et $\mathrm{al}^{16}$ corroborated this finding; they showed that all eyes exposed to $5 \mathrm{mg} /$ $\mathrm{ml}$ ICG for $3 \mathrm{~min}$ developed a visual field defect. The defects were only found in $25 \%$ of patients if immediate washout was performed and in no patients if $2.5 \mathrm{mg} / \mathrm{ml}$ was used. Nasal field defects were more common than temporal or concentric defects, and there were corresponding areas of optic disc pallor. Ando et al ${ }^{14}$ also found visual field defects, mainly nasally in patients receiving $0.5 \mathrm{mg} / \mathrm{ml}$ ICG compared to no stain or no peeling of the ILM.

Of concern, Gass et al ${ }^{19}$ found visual field defects despite using a very low $(0.05 \mathrm{mg} / \mathrm{ml})$ concentration of ICG. Another study showed that retinal nerve fibre layer thicknesses reduced in eyes with visual field defects after ICG-assisted vitrectomy for macular holes. ${ }^{26}$ The authors suggested that the postoperative visual field defects might have occurred secondary to ICG-mediated damage to the retinal nerve fibre layer.

\section{Studies failing to show visual field defects}

Several of the studies that tested for visual field defects failed to demonstrate ICG-mediated damage, with concentrations ranging from 0.05 to $0.25 \%$. Authors performed ICG washout immediately after or up to $15 \mathrm{~s}$ following intravitreal ICG injection. ${ }^{14,16,27}$ There are also many reports of visual field defects occurring before the introduction of ICG, with several possible aetiologies including retinal dehydration, elevated intraocular pressure, and direct trauma to the retinal nerve fibre layer or optic nerve. ${ }^{28-38}$

\section{Surgery for epiretinal membrane and macular pucker}

In surgery for diabetic macular oedema, macular pucker, and epiretinal membrane, the retina remains intact, unlike macular hole surgery, where there is a direct communication between the dye and the RPE and inner retinal elements. This might be expected to reduce the volume and concentration of dye reaching inner retinal elements, and some studies suggest that ICG is cleared more quickly from the eye in this setting. ${ }^{39}$ It is also interesting that the randomised study of epiretinal membrane surgery by Hillenkamp et $a l^{40}$ did not find visual field defects associated with ICG use, whereas a randomised study of macular hole surgery did. ${ }^{1}$

The molecular weight of ICG is 775, and experimental studies show that molecules of this size pass rapidly across the retina. ${ }^{41}$ Therefore, while an intact retina has the potential to reduce the level of dye exposure, it may not exclude it altogether. Further, if visual field defects occur secondary to retinal nerve fibre layer damage, as 
suggested by some reports, ${ }^{26,42}$ then a full-thickness defect may be less important. Haritoglou et al ${ }^{43}$ compared two consecutive series of patients undergoing macular pucker surgery and found that eyes with ICG had a significantly worse visual outcome than those without ICG. The authors used the same solution of dye $(5 \mathrm{mg} / \mathrm{ml}, 275 \mathrm{mOsm})$ in a second series of patients undergoing macular hole surgery ${ }^{20}$ and interestingly, the rate of visual field defects was identical in both macular hole and macular pucker cases (7 of 20 patients). Taken together, these two papers suggest that an intact retina does not protect against visual field defects.

\section{Surgery for diabetic macular oedema}

In addition to the presence of an intact retina, it might be expected that the metabolic changes associated with diabetes would have some effect on ICG safety. There are three reports of ICG use in patients undergoing surgery for diabetic macular oedema. Two showed a favourable safety profile, ${ }^{44,45}$ whereas one showed visual field defects, ${ }^{42}$ making it difficult to draw a conclusion.

\section{Electrophysiology}

A prospective study analysed visual outcome and multifocal electoretinograms (mfERG) in eyes undergoing macular hole surgery with and without staining with $5 \mathrm{mg} / \mathrm{ml}$ ICG. The unstained group had a better final VA, greater visual improvement, and a significantly greater improvement in the mfERG response. ${ }^{46}$ The significantly better outcomes without staining may suggest dye toxicity and the authors advocated the use of other dyes to assist ILM peeling.

Horio and Horiguchi ${ }^{47}$ also compared ILM peeling with and without ICG. They obtained significantly better visual outcomes without staining. MfERG did not show significant differences between both groups. The electrophysiological findings were interpreted as showing ICG-mediated damage to the ganglion cells and their axons, but the authors did not undertake visual field testing.

Summary: electrophysiology

1 One study showed ICG-assisted surgery adversely affected the multifocal electroretinogram, whereas another failed to show a significant effect

\section{Persistence of ICG}

Clinical studies have firmly established that ICG can persist for many months or possibly years after surgery. ${ }^{48}$ Many studies have shown persistence of the dye over approximately $6-7$ months in patients undergoing surgery for macular hole, ${ }^{39,49,50}$ with highly sensitive tests such as Heidelberg retina angiography, able to detect low levels of staining for up to 3 years. ${ }^{51}$ Hyperfluorescence is observed around the macular hole, at the optic disc, in the optic nerve fibres, and some authors found that it may be especially intense in the area along the vascular arcade. ${ }^{51}$ Over time, fluorescence appears to migrate from the macula towards the optic nerve, probably along the optic nerve fibres. ${ }^{52}$

Interestingly, areas of RPE atrophy lack hyperfluorescence, suggesting that the integrity of the RPE influences dye uptake or clearance. ${ }^{53}$ One study suggested that diabetes may slow dye elimination. ${ }^{54}$

Importantly, a causal link, or even an association between persistent staining and toxicity has not been established. Indeed, many eyes with persistent staining, even in association with RPE changes, have shown favourable visual outcomes. ${ }^{49}$

Summary: persistence of ICG

1 Clinical studies show that ICG can persist in the fundus for many months

2. Over time, residual ICG appears to move from the macula to the optic nerve

3 A causal link between persistent staining and toxicity has not been established

\section{Surgical techniques to minimize ICG toxicity}

Owing to concerns about ICG toxicity, several surgical techniques have been developed to protect the fovea. Facino et $a l^{55}$ added a small bubble of perfluorocarbon to protect myopic macular holes with retinal detachment, before injecting ICG. The aim was to prevent contact between the dye and the fovea, and the authors reported good anatomic and functional results in three cases. Olson $e t \mathrm{al}^{56}$ also obtained favourable results using the same technique in patients with idiopathic macular holes.

Two studies ${ }^{57,58}$ injected autologous whole blood over the fovea, to prevent ICG contact, with favourable visual and anatomic outcome in a total of 51 patients. No RPE changes were observed. Saito and Iid ${ }^{59}$ used viscoelastic as a barrier and also reported favourable outcomes.

Nakamura et $a l^{60}$ used autologous serum to wash out ICG at the end of the surgery. ICG was detected for 2.4 months after surgery with serum compared to 6.1 months without.

\footnotetext{
Summary: techniques to minimize ICG contact with the fovea

1 Agents placed on fovea to act as a barrier

- Perfluorocarbon

- Autologous whole blood

- Viscoelastic

2 Vitreous washout with serum
} 


\section{Summary of ICG clinical studies}

There are, at present, only two randomized clinical trials comparing surgery with and without ICG. One found a significant increase in visual field defects ${ }^{1}$ and neither found any effect on acuity. ${ }^{61}$ A large non-randomized study found that ICG was associated with lower rates of anatomic success, and worse acuity in those eyes with closed holes. ${ }^{21}$ The large number of non-randomized, observational studies are all potentially subject to selection bias, publication bias, and confounding, and many were not adequately powered. Their findings differ widely, but the most common observation appears to be visual field defects.

\section{Experimental studies}

\section{Animal studies}

Several reports ${ }^{49,62-64}$ evaluated the potential toxicity of ICG, at different concentrations, injected into the subretinal space in animal models. The rational for this approach is to simulate the contact that occurs between ICG and the RPE and photoreceptors when the dye is applied to full-thickness macular holes.

Subretinal injections of ICG $^{65}$ using concentrations at or above $1.25 \mathrm{mg} / \mathrm{ml}$ in rabbits have been reported to produce apoptosis and degenerative changes of the photoreceptors and RPE cells after a 3-day exposure. After a 4-week exposure, there was destruction of the outer retina and RPE in a dose-dependent manner. Hypo-osmolar ICG induced more damage to the retina than iso-osmolar solutions. As might be expected, subretinal ICG appears to be more damaging than intravitreal ICG. ${ }^{65}$

Yip et $a l^{66}$ performed an intravitreal injection of $1.0 \mathrm{mg} / \mathrm{ml}$ ICG in rat eyes with or without illumination from a standard endoillumination light pipe. Eyes with ICG and illumination showed a significant reduction in retinal ganglion cell density and increased outer nuclear layer thickness compared with negative controls, or eyes exposed to ICG, but not illumination. ${ }^{67}$

A series of studies in unvitrectomized rabbit and rat eyes showed that damage increases in relation to the concentration of intravitreal ICG, with electrophysiological changes occurring at lower concentrations than structural changes. ${ }^{68-70}$

A series of studies by different authors suggest that vitrectomy reduces ICG toxicity. ${ }^{68,71,72}$ These studies do not determine how this might occur, but one hypothesis is that vitrectomy enhances dye elimination. These three studies also give some indication of the lower threshold for toxicity in the vitrectomized rabbit eye. Following intravitreal injection of ICG, electrophysiological changes appear to occur with concentrations $>0.1 \mathrm{mg} / \mathrm{ml}$, whereas structural changes occur above $0.25 \mathrm{mg} / \mathrm{ml}$, although with somewhat different methodology.

Other animal studies have investigated the persistence of ICG in the retina and the optic nerve after intravitreal injection. Cekiç et $a l^{73}$ investigated the migration of ICG into the optic nerve after intravitreal injection in rabbits, with ICG found to have migrated into the intraorbital portion of the optic nerve, and persisting for 1 month. Paques $^{74}$ injected ICG in both the vitreous cavity and the lateral geniculate nucleus of unvitrectomized rats. Similar to Cekiç's findings, ICG was present in the ganglion cells and the optic nerve. Furthermore, retrograde labelling of the retina was demonstrated with the presence of ICG vesicles inside ganglion cells. Despite this, no toxic effect on ganglion cells was noted.

Czajka et $a l^{75}$ injected 0.5 and $1 \mathrm{mg} / \mathrm{ml}$ ICG in vitrectomized pigs either in fluid-filled or air-filled eyes. Fundoscopy showed more severe RPE atrophy in the animals with air-filled eyes than fluid-filled eyes. Outer retinal degeneration was more pronounced in the airfilled group. No inner retinal degeneration could be found in either group.

Gandorfer $e a^{76}$ looked at the toxicity of ICG in the cat retina. ICG staining of the ILM followed by illumination caused severe inner retinal damage. ICG without illumination resulted in focal ILM detachments associated with tearing of Müller cell endfeet.

In summary, animal studies do show some evidence of toxicity. Even low concentration $(0.1 \mathrm{mg} / \mathrm{ml}) \mathrm{ICG}$ can produce electrophysiological alterations of the b-wave, suggesting Müller cell dysfunction. At higher doses, starting from $2.5 \mathrm{mg} / \mathrm{ml}$, ICG can produce both structural and functional alterations of the retina in several species. Outer retina and RPE were significantly affected in several studies. Long illumination and dye exposure, absence of vitrectomy, an air-filled vitreous, and a central retinal location all predisposed to damage. Animal models have also verified the clinical observation that ICG can persist in the eye for an extended period of time.

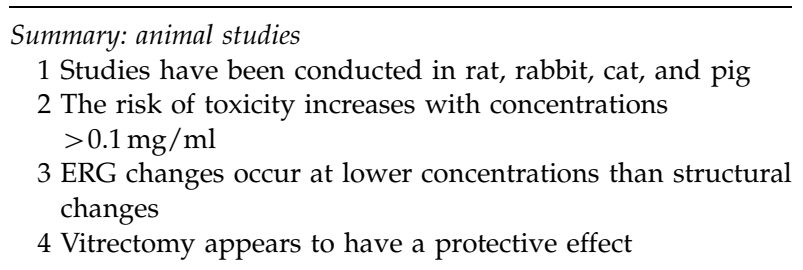

\section{Organ culture studies}

Saikia et $\mathrm{al}^{77}$ used a porcine organ culture exposed to iso-osmolar 0.1 and 1\% ICG for 1 and $30 \mathrm{~min}$, with and without illumination. There was no increase in TUNEL-positive cells using $0.1 \%$ ICG for $1 \mathrm{~min}$, but 
moderate apoptosis in retina exposed to the $1 \%$ solution for a 1-min, or with a 30-min exposure to $0.1 \%$ ICG. Severe apoptosis was found after a $30-\mathrm{min}$ exposure to $1 \%$ ICG. Concomitant application of light did not influence the degree of apoptosis. No signs of cell necrosis were found.

\section{Cell culture studies}

Cell cultures have been used extensively to investigate the safety of ICG. Studies have been reported on human RPE (ARPE-19), choroidal endothelial cells, Müller cells, and retinal ganglion cells from both human and rat.

As with the animal studies, some cell culture experiments suggest that the functional changes may occur at lower concentrations than structural changes. ${ }^{78}$ Sippy et $a l^{79}$ studied the effect of ICG $(1 \mathrm{mg} / \mathrm{ml})$ with or without light on human RPE cell cultures. RPE cells exposed to ICG showed no histological or ultrastructural changes at this concentration. However, those exposed to ICG alone or ICG plus light demonstrated a significant decrease in mitochondrial enzyme activity.

Murata et $a l^{80}$ studied the toxicity of 0.5 and $0.05 \mathrm{mg} /$ $\mathrm{ml}$ ICG on cultured retinal ganglion cells. At $0.5 \mathrm{mg} / \mathrm{ml}$, there was a significant decrease in the total number of cells and of resuzurin metabolic activity. Bcl-2 expression (a marker of apoptosis) increased with ICG concentrations $>0.05 \mathrm{mg} / \mathrm{ml}$, but at $0.05 \mathrm{mg} / \mathrm{ml}$, there was no toxicity.

Yam $e a^{81}$ studied the effect of light and two concentrations $(0.25$ and $2.5 \mathrm{mg} / \mathrm{ml})$ of ICG on human RPE cells in culture. ICG was applied for $1 \mathrm{~min}$, rinsed, and then cells were exposed to a light source (400$800 \mathrm{~nm}$ ). ICG at $0.25 \mathrm{mg} / \mathrm{ml}$ and without illumination appeared relatively safe. At $2.5 \mathrm{mg} / \mathrm{ml}$, a reduction in cell viability occurred, with considerable cell shrinkage without light exposure. The combination of ICG $(2.5 \mathrm{mg} /$ $\mathrm{ml}$ ) and light exposure resulted in the upregulation of apoptosis-related genes (p53, bax and protein p21).

Stalmans et $a l^{82}$ reported that ICG toxicity was related to the hypo-osmolarity of the solvent solution rather than ICG itself. At that time, the most commonly used ICG solution was hypo-osmolar, and the authors found that this induced RPE apoptosis, while infracyanine green diluted in $5 \%$ glucose produces an iso-osmolar solution and this did not affect RPE viability.

Rezai et al ${ }^{83}$ looked specifically at the rate of apoptosis among human RPE cell cultures exposed to different concentrations of ICG $(1-25 \mathrm{mg} / \mathrm{ml})$. All concentrations produced RPE apoptosis, with damage occurring in a dose-dependant manner. This occurred in the absence of light exposure and independent of the osmolarity of the solution.
Jackson $e t a l^{84}$ attempted to validate previous reports and study the interaction of osmolarity, concentration, and light exposure on RPE and Müller cells. In general, Müller cells appeared more vulnerable than RPE cells. Neither RPE cells nor Müller cells showed toxicity with a $0.5 \mathrm{mg} / \mathrm{ml}$ solution of ICG, but $1 \mathrm{mg} / \mathrm{ml}$ ICG produced toxicity. Brief exposure to hypo-osmolarity alone did not produce toxicity, even with saline solutions as low $181 \mathrm{mOsm}$, but when low osmolarity and ICG were combined, this produced cell damage, as did concomitant light exposure.

Worryingly, Hsu et al ${ }^{85}$ reported that very low concentrations of ICG $(0.01 \mathrm{mg} / \mathrm{ml})$ were capable to produce a relatively toxic effect on cultured human RPE cells in the absence of illumination, despite using an isoosmolar solution.

An interesting study by Lai et al ${ }^{58}$ investigated the protective effect of whole blood and plasma on RPE cultures exposed to increasing concentrations of ICG $(0.05-5 \mathrm{mg} / \mathrm{ml})$ and halogen light exposure for $20 \mathrm{~min}$. A mitochondrial dehydrogenase assay failed to show any reduction in cell viability, when these agents were added.

Mennel et $a l^{78}$ assessed the outer blood-retinal-barrier by measuring the transepithelial electrical resistance of RPE cells in culture. Human RPE cells and choroidal endothelial cells were cultured in monolayers on semipermeable membranes representing an in vitro model of the outer blood-retinal barrier. They modelled fluid-filled and air-filled eyes by adding ICG solution to culture media or cell monolayers, respectively. In the fluid-filled model, transepithelial resistance remained intact at all ICG concentrations, whereas in the air-filled model, 0.5 and $5 \mathrm{mg} / \mathrm{ml}$ ICG produced a significant decrease in transepithelial electrical resistance.

Transmission electron microscopy did not show any morphological change except when using $5 \mathrm{mg} / \mathrm{ml}$ ICG in the air-filled model.

Recently Kunikata et $a l^{86}$ reported a protective role of low temperature $\left(4^{\circ} \mathrm{C}\right)$ in cultured ARPE-19 cells exposed to ICG over a range of concentrations. At $37^{\circ} \mathrm{C}$, cell viability was reduced with concentrations $>0.25 \mathrm{mg} / \mathrm{ml}$; at $4{ }^{\circ} \mathrm{C}$ this safety threshold increased, with no toxicity below $5 \mathrm{mg} / \mathrm{ml}$.

Three reports by Jin et $a l^{87}$, Iriyama et $a l^{88}$ and Iriyama et $a l^{89}$ investigated the potential toxicity of ICG at the retinal ganglion cell layer. They found that cultured retinal ganglion cells exposed to ICG for $10 \mathrm{~s}$ to $30 \mathrm{~min}$ showed almost no damage. By contrast, longer exposure to ICG resulted in cell loss in a dose-dependent manner, with effects measurable up to 14 days after exposure to ICG and light.

Some studies identified experimental artefacts that have the potential to produce false measures of toxicity. The mitochondrial enzyme assay used by Sippy et $a l^{79}$ 
and many other researchers assesses the conversion of an optically clear precursor to a blue formazan reaction product, produced by the mitochondria of healthy cells. Residual staining of the cell monolayer by dyes may interfere with the optical measurement of this reaction product. This produces a concentration-dependent, falsely low measure of cell viability, unless corrections are made for baseline staining. ${ }^{84}$ Further, Ikagawa et al $l^{90}$ found that ICG could damage RPE cell cultures by altering nutrient molecules in the culture media. Over a 12-h exposure, ICG resulted in serum molecules becomes insoluble, with resultant adverse effects on cell survival.

In summary, these cell culture studies show that, under certain conditions, ICG has the potential to produce toxicity in RPE cells, glia, and retinal ganglion cells. While not all studies concur, the trends emerging are that the threshold for ICG toxicity is reduced with longer exposure, higher concentration, light exposure, concurrent air exposure, and hypo-osmolarity.

From this, it follows that surgeons using ICG should select a concentration below $0.5 \mathrm{mg} / \mathrm{ml}$, preferably below $0.05 \mathrm{mg} / \mathrm{ml}$. Exposure time should be the minimum required to achieve staining, and the endoilluminator should be kept away from the fovea as much as possible. Instilling ICG in a fluid-filled eye may be preferable to an air-filled eye: this is easier if Hartman's solution is used as the infusate, as this has a lower density than most balanced saline solutions (BSS), encouraging ICG to settle over the macula under gravity. Hypo-osmolar solutions should be avoided altogether - this is possible if glucose is used as the diluent rather than distiled water. A potential protective effect of whole blood applied to the macula, and the use of a cooled infusate have both been identified in culture, but neither has been tested in an adequate number of patients to draw a conclusion. Caution also needs to be exercised in translating findings in avascular, often immortalized, single-cell lines, to the situation in vivo, where non-replicating, mature cells exist in a multicellular environment. More so, as some studies show that mitochondrial assays need careful modification to avoid inaccuracy, and other studies show potential experimental artefact, with ICG-mediated damage to nutrient molecules in the culture media.

\footnotetext{
Summary: cell culture studies

1 ICG has been tested using retinal pigment epithelium, choroidal endothelial cells, Müller cells, and retinal ganglion cells

2 Toxicity increases with increasing concentration and exposure time

3 Few studies show toxicity at or below $0.05 \mathrm{mg} / \mathrm{ml}$

4 Hypo-osmolarity and concurrent light exposure may increase toxicity
}

\section{Histology and cadaveric studies}

Histological analysis of human retinal and epiretinal tissue has provided useful information on potential ICG toxicity, although the authors' conclusions differ in many respects. Analysis has been completed on eye bank eyes, and on tissue excised during vitrectomy. The key questions to emerge are whether ICG acts as a photosensitizer, damages tissue, and alters the surgical cleavage plane such that deeper retinal elements are removed with the ILM.

Burk et $a l^{91}$ performed morphological analysis of the ILM in 11 donor eyes. Eyes underwent an open-sky vitrectomy followed by a 5 -min exposure to $5 \mathrm{mg} / \mathrm{ml}$ ICG. Macroscopically, the ILM was well stained with this exposure routine. Tissue was then removed for light and electron microscopy. All specimens contained ILM, without retinal or glial cell elements. There was a clear distinction between the ILM and the retina, suggesting ICG did not alter the cleavage plane.

Kwok et al ${ }^{15}$ obtained six complete histological ICG-stained ILM specimens from 10 macular hole surgeries. Two of six ILM specimens had a small amount of epiretinal membrane. Myofibrocytes were noted in the ILM, either scattered or as a single layer, in three cases.

Drs Gandorfer, Haritoglou, and Kampik in Munich have provided a large number of papers on ICG use, including the earliest articles raising concern about toxicity, with many clinical and experimental studies since. Initially, Gandorfer et $a l^{92}$ showed in patients with macular hole (five patients) or diffuse macular oedema (five patients) that ICG was capable of staining the ILM after vitrectomy and cortex removal. Light and transmission electron microscopy revealed that the ILM was effectively stained and removed in all cases.

Haritoglou et $a l^{20}$ analysed the ultrastructure of excised ILM by light and transmission electron microscopy in 20 eyes that had undergone macular hole surgery with ICG staining. They found that ICG-stained specimens had cellular elements resembling the plasma membrane of Müller cells, and other undetermined retinal elements adherent to the retinal side of the ILM. The authors contended that the presence of these deeper retinal elements suggests that ICG alters the surgical cleavage plane deep to the ILM, with associated retinal damage. Gandorfer et $a l^{93}$ reported similar findings in 10 ILM specimens removed after ICG staining during surgery for idiopathic macular hole.

The same team ${ }^{94}$ reported on the ultrastructure of human donor eyes exposed to $5 \mathrm{mg} / \mathrm{ml} \mathrm{ICG}$, and different wavelength light. Electron microscopy showed severe retinal damage to the inner retina, including loss 
of the ILM, cellular disorganization, and fragmentation of the cytoplasm at wavelengths beyond $620 \mathrm{~nm}$. ICG staining alone, or in combination with wavelengths of $380-620 \mathrm{~nm}$, produced rupture of Müller cells with detachment of the ILM. They concluded that ICG alone could induce debridement of Müller cell components, and that the exposure to light, especially wavelengths above $620 \mathrm{~nm}$, induced phototoxic damage to the inner retina.

When other authors attempted to validate these findings in freshly enucleated pig eyes, they failed to show equivalent results. ${ }^{95}$ However, La Heij et $a l^{96}$ did find extraneous tissue in their analysis of ILM specimens removed after ICG-assisted peeling.

Immunohistochemistry revealed ILM positivity for GFAP (a glial marker) in 8 of 10 specimens. Two other specimens were positive for S-100, indicating the presence of neural cells or ganglion cells.

Haritoglou $e t a l^{97}$ used reflection spectroscopy to study the absorption spectrum of ICG adsorbed onto the retinal surface of cadaver eyes. Compared to ICG in saline or water, the absorption profile showed less variation in relation to concentration and time, with twin peaks at 736 and $800 \mathrm{~nm}$ persisting over the 13-day experiment. The question that remains unanswered is how the natural light that reaches the macular interacts with residual ICG.

In conclusion, some histological studies suggest that ICG-assisted peeling of the ILM may result in morphological changes to the ILM and the underlying retina. Additionally, damage may be aggravated by light exposure, particularly longer wavelength light that overlaps with the absorption spectrum of ICG. ICG may also alter the cleavage plane, such that the ILM is removed with adherent cellular constituents. It should be noted, however, that other authors have shown cellular constituents associated with ILM removal, in the absence of ICG. Further, some studies have failed to demonstrate ultrastructural damage of excised ILM, and it is not certain that all damage relates to ICG per se. On balance, ICG appears to be damaging, but experimental artefact may be a factor.

\footnotetext{
Summary: histological studies

1 Light and electron microscopy and immunohistochemistry have been used to study excised surgical specimens and cadaver eyes exposed to ICG

2 ICG may alter the cleavage plane, with deeper retinal elements adherent to the peeled ILM

3 ICG combined with long wavelength light $(>620 \mathrm{~nm}$ ) may increase cell damage

4 The relevance of cadaver eyes to the in vivo use of ICG is not known

5 It is not certain that all the changes observed in surgical specimens were caused by ICG
}

\section{Summary of experimental studies}

Authors have utilized a wide range of methodologies to investigate the safety of ICG as a vital stain. These have included cell culture, analysis of excised specimens, mock surgery in enucleated eyes, and in vivo animal experiments. The findings differ and no model perfectly simulates the clinical application of ICG in humans, that is, brief delivery to a vascularized, immunologically active, multicellular environment in predominantly mature patients. Some data suggest that ICG is safe in the concentrations used clinically, whereas others show ICG producing profound cellular damage. Further, some studies show quite different results using very similar methodology. Reading the experimental literature as a whole, there are more studies showing toxicity than safety, but publication bias cannot be excluded.

\section{Infracyanine green}

\section{Background}

Infracyanine green is a proprietary solution containing the same fluorophore found in ICG. It differs from ICG in two respects. First, infracyanine green is iodine free. Second, infracyanine green tends to precipitate in water, and therefore it is provided with $5 \%$ glucose as the diluent. Infracyanine green prepared in this glucose diluent is near to iso-osmolar (294-314 mOsm), relative to intraocular tissue, whereas ICG prepared in water is hypo-osmolar. As the studies of ICG showed that its low osmolarity might be at least partly responsible for toxicity, it has been suggested that infracyanine green may be a safer alternative.

\section{Clinical studies}

At the time of writing, there were no randomized clinical studies of infracyanine green. The use of infracyanine green $(0.5-2.0 \mathrm{mg} / \mathrm{ml})$ has, however, been reported in prospective observational studies of macular hole, epiretinal membrane, and macular oedema, ${ }^{98-102}$ and in several retrospective studies of macular hole surgery. ${ }^{102-106}$

Most studies show a favourable anatomic and visual outcome with no obvious toxicity. In contrast, one observational series suggested that infracyanine green might be associated with an adverse outcome. This compared the visual outcome in 29 patients undergoing the removal of the ILM or epiretinal membranes with infracyanine green to 14 patients in whom trypan blue was used instead. ${ }^{107}$ Compared to the preoperative status, only the trypan blue group showed a significant improvement in acuity, with no reduction in the central visual field. In contrast, the infracyanine group showed a 
non-significant improvement in acuity, but a significant attenuation of central visual fields. The authors concluded that the central visual field may be a more sensitive measure of damage from infracyanine green than acuity. Of note, however, there was no significant difference in visual outcome when directly comparing trypan blue and infracyanine green groups.

\section{Experimental studies}

Human RPE cell culture has been extensively used to investigate the safety of infracyanine green. ${ }^{82,84,108,109}$ Mature confluent RPE monolayers appear to be more resistant to potential toxicity than younger cells. This may be of relevance, as in adult human eyes, RPE cells exist as a monolayer of mature non-dividing cells. Isoosmolar infracyanine green dissolved in glucose solution, at a concentration below $5 \mathrm{mg} / \mathrm{ml}$ and with exposure times ranging from 2 min to 6 days did not alter RPE cell survival in culture. ${ }^{108}$ Jackson et al ${ }^{84}$ exposed both RPE and Müller cell monolayers to a range of concentrations of infracyanine green, up to $5 \mathrm{mg} / \mathrm{ml}$. RPE cells failed to show significant damage, but Müller cells did show damage with a $5 \mathrm{mg} / \mathrm{ml}$ solution. When exposure to infracyanine green was combined with a 5-min illumination by a vitrectomy endolight powered by a xenon light source, there was some additional damage in RPE cells, but not relative to an active control (light alone). Müller cells did not show phototoxicity.

Finally, Stalmans et $a l^{82}$ exposed RPE cell cultures to different solutions for $20 \mathrm{~min}$. These solutions included BSS, ICG in BSS, glucose 5\% alone, and infracyanine green in glucose $5 \%$. The main differences between the solutions were their osmolarity. Hypo-osmolar solutions with or without indocyanine resulted in higher cell death. Iso-osmolar solutions (including those with infracyanine green) did not alter RPE cell survival rate. They concluded that the toxicity of ICG on RPE cells is probably related to the hypo-osmolarity of the solvent and may be avoided by using infracyanine green dissolved in glucose $5 \%$.

Taken together, these studies suggest that mature RPE cell culture monolayers do not show toxicity when exposed to low concentration infracyanine with a short exposure time. However, high concentration exposure, combined with low osmolarity or bright endoilumination may increase the risk of damage. It is also important to note the cautionary comments given in the section on ICG, regarding the relevance of cell culture to the clinical environment.

Haritoglou et al ${ }^{110}$ injected postmortem human eyes with either iso-osmolar infracyanine green dissolved in glucose solution (SERB, France), or ICG in saline solution (ICG Pulsion, Germany). Eyes were then illuminated with a commonly used vitrectomy light source, and compared with unilluminated controls. Electron microscopy revealed disorganization of the inner retina and complete loss of ILM after the application of both ICG solutions and illumination. ${ }^{110}$ In contrast, no abnormalities were found after the application of both dyes without illumination and in unstained control specimens. Despite the hypothesis that the glucose solvent might favourably alter the light-absorbing proprieties of the dye and reduce the potential for photosensitivity, this was not found to be the case. Again, as with ICG, the validity of using enucleated human eyes to model in vivo toxicity is not known.

As with ICG, immunohistochemistry of tissue removed during infracyanine green-assisted surgery has shown Müller cell footplates, neural cells, and ganglion cells, but whether this can be attributed to alteration in the cleavage plane, or a normal consequence of tissue excision in not known. ${ }^{96-111}$ Despite the presence of various cell types in excised specimens, no clinical evidence of dye-related toxicity was reported in a study by Ullern et al. ${ }^{102}$ The specimens removed in macular hole surgery disclosed that few cells, were very thin, and were scarcely positive for vimentin using immunohistochemistry, suggesting that the surgical cleavage plane was not altered. ${ }^{103}$

\footnotetext{
Summary: infracyanine green

1 Infracyanine green contains the same dye as ICG

2 Infracyanine green is iodine free and comes packaged with glucose as the diluent - this produces an iso-osmolar solution

3 ICG contains iodine and comes packaged with water as the diluent - this produces a hypo-osmolar solution (ICG can, however, be dissolved in glucose)

4 Most clinical and experimental reports show a favourable outcome

5 There are fewer studies of infracyanine green than ICG
}

\section{Conclusion}

Given that infracyanine green contains the same fluorophore as ICG, it is perhaps unsurprising that many of the controversies run parallel. The key issue is related to whether or not its iso-osmolarity confers a safety benefit. Unfortunately, the experimental evidence points in different directions and randomized trials have not been completed. However, as a general statement, the proportion of clinical studies showing safety appears to be higher than with ICG, although with a much smaller evidence base. Further, at least some studies show ICG toxicity is aggravated, or perhaps mediated by hypo-osmolarity, so there is an argument for using infracyanine green instead of ICG dissolved in water. 
Now that many surgeons dissolve ICG in BSS or glucose, it is not certain that this theoretical advantage remains.

\section{Conclusion}

As with many surgical techniques and devices, ICG's use as a vital stain was not subjected to the rigorous and formalized safety testing that's required for novel pharmaceutical agents. Rather, its introduction most likely reflects its availability and familiarity to ophthalmologists, rather than a systematic assessment ${ }^{94,95}$ of the many hundreds of dyes available and their individual merits.

After initial enthusiasm, many clinicians discontinued the use of ICG as an intraoperative vital stain because of concerns about toxicity. There are, however, many who continue to use it without manifest toxicity. It seems, therefore, that if ICG is toxic, the effects are subtle.

Assuming that any ICG toxicity is subtle, it may be difficult to detect for several reasons. Firstly, most clinical reports are imperfect. Only two randomized clinical trial directly assessed ICG toxicity. The first showed increased visual field defects with mircoperimetry and this, in itself, raises concerns, but it may not have been sufficiently powered to detect subtle differences in VA. ${ }^{1}$ The second randomized trial of 60 patients found two visual field defects in the ICG group with no significant difference in VA ${ }^{61}$ With so few randomized clinical trials, it is extremely difficult to draw a conclusion on ICG safety. Most other studies were small observational series, often without a comparator. Secondly, many of the component steps of vitrectomy can damage VA, or cause visual field defects, and these may confound analysis. Thirdly, an underlying disease such as macular hole or epiretinal membrane may mean that postoperative visual function is impaired and subtle defects easily missed.

Like the clinical studies, it is difficult to reach a firm conclusion when analysing the experimental research on ICG toxicity. It is impossible to develop a perfect experimental model, as few cell culture or animal models can fully replicate the clinical application of ICG in humans. Nonetheless, these studies do point to emerging trends, many of which are consistent with our understanding of toxicology in general. These studies show that toxicity may be aggravated by solutions that contain a high concentration of ICG, low osmolarity, and long exposure times. Endoillumination may also aggravate cell damage, possibly by direct interaction with ICG, which may act as a photosensitizer. While intraoperative endoillumination was not standardized across studies, it is reasonable to mitigate the risk of light-mediated damage by reducing not only the duration of macular illumination but also the power setting. Increasing the distance from the retina is likely to be beneficial, with halogen light sources offering a theoretically lower risk than xenon units.

In the absence of robust clinical or experimental evidence, clinicians might reasonably continue to use ICG, but the method of application should take account of the evidence that exists. They should, therefore, use low concentration solutions, such as $0.05 \mathrm{mg} / \mathrm{ml}$, in fluidfilled eyes, and use diluents such as glucose to prepare an iso-osmolar solution. Brief exposure, ideally $10 \mathrm{~s}$ or less, reduces the risk of damage, as may thorough rinsing from the eye. It would also be prudent to avoid bright, proximal illumination with the endolight, when ICG remains visible on the surface of the retina. Infracyanine green may be safer than ICG and stains the ILM as effectively.

An alternative analysis of the literature is to accept that even if the studies are imperfect, there is an increasing body of evidence to show that the safety margin of ICG is narrow and toxicity is a distinct possibility. At the very least, patients should be warned of this. Now that other vital stains are readily available, it could be argued that the use of ICG is inappropriate.

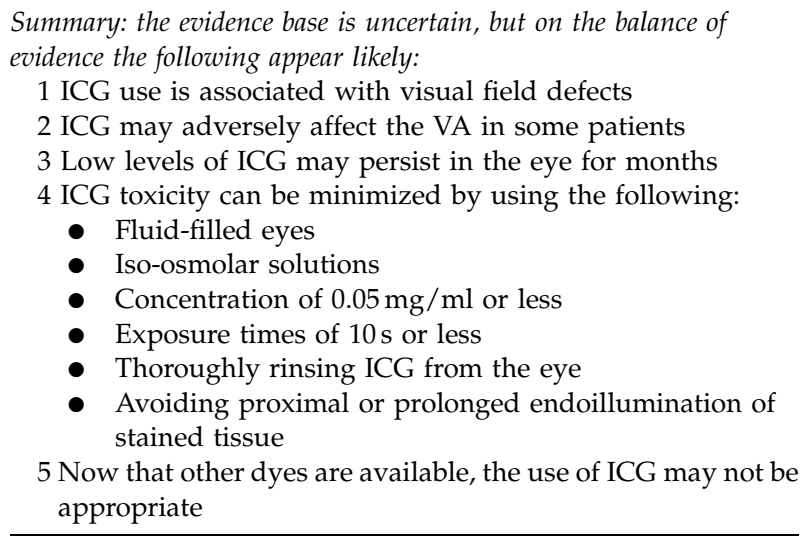

\section{References}

1 Beutel J, Dahmen G, Ziegler A, Hoerauf H. Internal limiting membrane peeling with indocyanine green or trypan blue in macular hole surgery: a randomized trial. Arch Ophthalmol 2007; 125: 326-332.

2 Kwok AK, Lai TY, Yuen KS, Tam BS, Wong VW. Macular hole surgery with or without indocyanine green-stained internal limiting membrane peeling. Clin Experiment Ophthalmol 2003; 31: 470-475.

3 Kwok AK, Lai TY, Yew DT, Li WW. Internal limiting membrane staining with various concentrations of indocyanine green dye under air in macular surgeries. Am J Ophthalmol 2003; 136: 223-230.

4 Da Mata AP, Burk SE, Riemann CD, Rosa RHJ, Snyder ME, Petersen MR et al. Indocyanine green-assisted peeling of the retinal internal limiting membrane during vitrectomy surgery for macular hole repair. Ophthalmology 2001; 108: 1187-1192. 
5 Da Mata AP, Burk SE, Foster RE, Riemann CD, Petersen $\mathrm{MR}, \mathrm{Nehemy} \mathrm{MB}$ et al. Long-term follow-up of indocyanine green-assisted peeling of the retinal internal limiting membrane during vitrectomy surgery for idiopathic macular hole repair. Ophthalmology 2004; 111: 2246-2253.

6 Kumar A, Prakash G, Singh RP. Indocyanine green enhanced maculorhexis in macular hole surgery. Indian $J$ Ophthalmol 2002; 50: 123-126.

7 Apostolopoulos MN, Koutsandrea CN, Moschos MN, Alonistiotis DA, Papaspyrou AE, Mallias JA et al. Evaluation of successful macular hole surgery by optical coherence tomography and multifocal electroretinography. Am J Ophthalmol 2002; 134: 667-674.

8 Lochhead J, Jones E, Chui D, Lake S, Karia N, Patel CK et al. Outcome of ICG-assisted ILM peel in macular hole surgery. Eye 2004; 18: 804-808.

9 Sheidow TG, Blinder KJ, Holekamp N, Joseph D, Shah G, Grand MG et al. Outcome results in macular hole surgery: an evaluation of internal limiting membrane peeling with and without indocyanine green. Ophthalmology 2003; 110: 1697-1701.

10 Wolf S, Reichel MB, Wiedemann P, Schnurrbusch UE. Clinical findings in macular hole surgery with indocyanine green-assisted peeling of the internal limiting membrane. Graefes Arch Clin Exp Ophthalmol 2003; 241: 589-592.

11 Das T, Parida S, Majji AB. Does internal limiting membrane peeling in macular hole surgery improve reading vision? Indian J Ophthalmol 2003; 51: 251-254.

12 Lai MM, Williams GA. Anatomical and visual outcomes of idiopathic macular hole surgery with internal limiting membrane removal using low-concentration indocyanine green. Retina 2007; 27: 477-482.

13 Kadonosono K, Itoh N, Uchio E, Nakamura S, Ohno S. Staining of internal limiting membrane in macular hole surgery. Arch Ophthalmol 2000; 118: 1116-1118.

14 Ando F, Sasano K, Suzuki F, Ohba N. Indocyanine greenassisted ILM peeling in macular hole surgery revisited. Am J Ophthalmol 2004; 138: 886-887.

15 Kwok AK, Li WW, Pang CP, Lai TY, Yam GH, Chan NR et al. Indocyanine green staining and removal of internal limiting membrane in macular hole surgery: histology and outcome. Am J Ophthalmol 2001; 132: 178-183.

16 Kanda S, Uemura A, Yamashita T, Kita H, Yamakiri K, Sakamoto T. Visual field defects after intravitreous administration of indocyanine green in macular hole surgery. Arch Ophthalmol 2004; 122: 1447-1451.

17 Nagai N, Ishida S, Shinoda K, Imamura Y, Noda K, Inoue M. Surgical effects and complications of indocyanine green-assisted internal limiting membrane peeling for idiopathic macular hole. Acta Ophthalmol Scand 2007; 85: 883-889.

18 Tsuiki E, Fujikawa A, Miyamura N, Yamada K, Mishima K, Kitaoka T. Visual field defects after macular hole surgery with indocyanine green-assisted internal limiting membrane peeling. Am J Ophthalmol 2007; 143: 704-705.

19 Gass CA, Haritoglou C, Schaumberger M, Kampik A. Functional outcome of macular hole surgery with and without indocyanine green-assisted peeling of the internal limiting membrane. Graefes Arch Clin Exp Ophthalmol 2003; 241: 716-720.

20 Haritoglou C, Gandorfer A, Gass CA, Schaumberger M, Ulbig MW, Kampik A. Indocyanine green-assisted peeling of the internal limiting membrane in macular hole surgery affects visual outcome: a clinicopathologic correlation. Am J Ophthalmol 2002; 134: 836-841.

21 Tognetto D, Grandin R, Sanguinetti G, Minutola D, Di Nicola M, Di Mascio R et al. Internal limiting membrane removal during macular hole surgery: results of a multicenter retrospective study. Ophthalmology 2006; 113: 1401-1410.

22 Engelbrecht NE, Freeman J, Sternberg PJ, Aaberg TMS, Aaberg TMJ, Martin DF et al. Retinal pigment epithelial changes after macular hole surgery with indocyanine green-assisted internal limiting membrane peeling. Am J Ophthalmol 2002; 133: 89-94.

23 Poliner LS, Tornambe PE. Retinal pigment epitheliopathy after macular hole surgery. Ophthalmology 1992; 99: 1671-1677.

24 Mavrofrides E, Smiddy WE, Kitchens JW, Salicone A, Feuer W. Indocyanine green-assisted internal limiting membrane peeling for macular holes: toxicity? Retina 2006; 26: 637-644.

25 Miura M, Elsner AE, Osako M, Iwasaki T, Okano T, Usui M. Dissociated optic nerve fiber layer appearance after internal limiting membrane peeling for idiopathic macular hole. Retina 2003; 23: 561-563.

26 Yamashita T, Uemura A, Kita H, Sakamoto T. Analysis of the retinal nerve fiber layer after indocyanine greenassisted vitrectomy for idiopathic macular holes. Ophthalmology 2006; 113: 280-284.

27 Haritoglou C, Neubauer AS, Gandorfer A, Thiel M, Kampik A. Indocyanine green for successful repair of a long-standing macular hole. Am J Ophthalmol 2003; 136: 389-391.

28 Welch JC. Dehydration injury as a possible cause of visual field defect after pars plana vitrectomy for macular hole. Am J Ophthalmol 1997; 124: 698-699.

29 Hirata A, Yonemura N, Hasumura T, Murata Y, Negi A. Effect of infusion air pressure on visual field defects after macular hole surgery. Am J Ophthalmol 2000; 130: 611-616.

30 Kerrison JB, Haller JA, Elman M, Miller NR. Visual field loss following vitreous surgery. Arch Ophthalmol 1996; 114: 564-569.

31 Melberg NS, Thomas MA. Visual field loss after pars plana vitrectomy with air/fluid exchange. Am J Ophthalmol 1995; 120: 386-388.

32 Yan H, Dhurjon L, Chow DR, Williams D, Chen JC. Visual field defect after pars plana vitrectomy. Ophthalmology 1998; 105: 1612-1616.

33 Ito Y, Terasaki H, Takahashi A, Yamakoshi T, Kondo M, Nakamura M. Dissociated optic nerve fiber layer appearance after internal limiting membrane peeling for idiopathic macular holes. Ophthalmology 2005; 112 1415-1420.

34 Boldt HC, Munden PM, Folk JC, Mehaffey MG. Visual field defects after macular hole surgery. Am J Ophthalmol 1996; 122: 371-381.

35 Paques M, Massin P, Santiago PY, Spielmann AC, Gaudric A. Visual field loss after vitrectomy for full-thickness macular holes. Am J Ophthalmol 1997; 124: 88-94.

36 Arima T, Uemura A, Otsuka S, Doi N, Nakao K. Macular hole surgery-associated peripheral visual field loss. Jpn J Ophthalmol 1998; 42: 476-483.

37 Ohji M, Nao-I N, Saito Y, Hayashi A, Tano Y. Prevention of visual field defect after macular hole surgery by passing air used for fluid-air exchange through water. Am J Ophthalmol 1999; 127: 62-66. 
38 Hutton WL, Fuller DG, Snyder WB, Fellman RL, Swanson WH. Visual field defects after macular hole surgery. A new finding. Ophthalmology 1996; 103: 2152-2158; discussion 2158-9.

39 Nakamura H, Hayakawa K, Imaizumi A, Sakai M, Sawaguchi S. Persistence of retinal indocyanine green dye following vitreous surgery. Ophthalmic Surg Lasers Imaging 2005; 36: 37-45.

40 Hillenkamp J, Saikia P, Gora F, Sachs HG, Lohmann CP, Roider J et al. Macular function and morphology after peeling of idiopathic epiretinal membrane with and without the assistance of indocyanine green. $\mathrm{Br} J$ Ophthalmol 2005; 89: 437-443.

41 Jackson TL, Antcliff RJ, Hillenkamp J, Marshall J. Human retinal molecular weight exclusion limit and estimate of species variation. Invest Ophthalmol Vis Sci 2003; 44: 2141-2146.

42 Ando F, Yasui O, Hirose H, Ohba N. Optic nerve atrophy after vitrectomy with indocyanine green-assisted internal limiting membrane peeling in diffuse diabetic macular edema. Adverse effect of ICG-assisted ILM peeling. Graefes Arch Clin Exp Ophthalmol 2004; 242: 995-999.

43 Haritoglou C, Gandorfer A, Gass CA, Schaumberger M, Ulbig MW, Kampik A. The effect of indocyanine-green on functional outcome of macular pucker surgery. Am J Ophthalmol 2003; 135: 328-337.

44 Bardak Y, Cekic O, Tig SU. Comparison of ICG-assisted ILM peeling and triamcinolone-assisted posterior vitreous removal in diffuse diabetic macular oedema. Eye 2006; 20 1357-1359.

45 Kamura Y, Sato Y, Isomae T, Shimada H. Effects of internal limiting membrane peeling in vitrectomy on diabetic cystoid macular edema patients. Jpn J Ophthalmol 2005; 49: 297-300.

46 Ferencz M, Somfai GM, Farkas A, Kovacs I, Lesch B, Recsan $\mathrm{Z}$ et al. Functional assessment of the possible toxicity of indocyanine green dye in macular hole surgery. Am J Ophthalmol 2006; 142: 765-770.

47 Horio N, Horiguchi M. Effect on visual outcome after macular hole surgery when staining the internal limiting membrane with indocyanine green dye. Arch Ophthalmol 2004; 122: 992-996.

48 Kersey TL, Bolton A, Patel CK. Serial autofluorescence imaging over two years following indocyanine greenassisted internal limiting membrane peel for macular hole. Clin Experiment Ophthalmol 2005; 33: 538-539.

49 Hirata A, Inomata Y, Kawaji T, Tanihara H. Persistent subretinal indocyanine green induces retinal pigment epithelium atrophy. Am J Ophthalmol 2003; 136: 353-355.

50 Ciardella AP, Schiff W, Barile G, Vidne O, Sparrow J, Langton $\mathrm{K}$ et al. Persistent indocyanine green fluorescence after vitrectomy for macular hole. Am J Ophthalmol 2003; 136: $174-177$.

51 Sekiryu T, Iida T. Long-term observation of fundus infrared fluorescence after indocyanine green-assisted vitrectomy. Retina 2007; 27: 190-197.

52 Sayanagi K, Ikuno Y, Soga K, Sawa M, Oshima Y, Kamei M et al. Residual indocyanine green fluorescence pattern after vitrectomy for idiopathic macular hole with internal limiting membrane peeling. Br J Ophthalmol 2007; 91 939-944.

53 Sayanagi K, Ikuno Y, Soga K, Sawa M, Tano Y. Residual indocyanine green fluorescence pattern after vitrectomy with internal limiting membrane peeling in high myopia. Am J Ophthalmol 2007; 144: 600-607.

54 Ashikari M, Ozeki H, Tomida K, Sakurai E, Tamai K, Ogura Y. Long-term retention of dye after indocyanine green-assisted internal limiting membrane peeling. Jpn J Ophthalmol 2006; 50: 349-353.

55 Facino M, Mochi B, Lai S, Terrile R. A simple way to prevent indocyanine green from entering the subretinal space during vitrectomy for retinal detachment due to myopic macular hole. Eur J Ophthalmol 2004; 14: 269-271.

56 Olson JL, On AV, Mandava N. Protecting the retinal pigment epithelium during macular hole surgery. Clin Experiment Ophthalmol 2005; 33: 576-577.

57 Rizzo S, Belting C, Genovesi-Ebert F, Vento A, Cresti F. Modified technique for safer indocyanine-green-assisted peeling of the internal limiting membrane during vitrectomy for macular hole repair. Graefes Arch Clin Exp Ophthalmol 2006; 244: 1615-1619.

58 Lai CC, Wu WC, Chuang LH, Yeung L, Chen TL, Lin KK. Prevention of indocyanine green toxicity on retinal pigment epithelium with whole blood in stain-assisted macular hole surgery. Ophthalmology 2005; 112: 1409-1414.

59 Saito M, Iida T. A surgical technique to protect the macular hole in indocyanine green-assisted vitrectomy. Ophthalmic Surg Lasers Imaging 2006; 37: 511-515.

60 Nakamura H, Hayakawa K, Sawaguchi S, Gaja T. Removal of retinal indocyanine green dye by autologous serum irrigation in macular hole surgery. Retina 2005; 25: 736-741.

61 Hillenkamp J, Saikia P, Herrmann WA, Framme C, Gabel VP, Sachs HG. Surgical removal of idiopathic epiretinal membrane with or without the assistance of indocyanine green: a randomised controlled clinical trial. Graefes Arch Clin Exp Ophthalmol 2007; 245: 973-979.

62 Lee JE, Yoon TJ, Oum BS, Lee JS, Choi HY. Toxicity of indocyanine green injected into the subretinal space: subretinal toxicity of indocyanine green. Retina 2003; 23: 675-681.

63 Kawaji T, Hirata A, Inomata Y, Koga T, Tanihara H. Morphological damage in rabbit retina caused by subretinal injection of indocyanine green. Graefes Arch Clin Exp Ophthalmol 2004; 242: 158-164.

64 Maia M, Kellner L, de Juan EJ, Smith R, Farah ME, Margalit $\mathrm{E}$ et al. Effects of indocyanine green injection on the retinal surface and into the subretinal space in rabbits. Retina 2004; 24: 80-91.

65 Penha FM, Maia M, Eid Farah M, Principe AH, Freymuller $\mathrm{EH}$, Maia A et al. Effects of subretinal injections of indocyanine green, trypan blue, and glucose in rabbit eyes. Ophthalmology 2007; 114: 899-908.

66 Yip HK, Lai TY, So KF, Kwok AK. Retinal ganglion cells toxicity caused by photosensitising effects of intravitreal indocyanine green with illumination in rat eyes. $\mathrm{Br} \mathrm{J}$ Ophthalmol 2006; 90: 99-102.

67 Kwok AK, Lai TY, Yeung CK, Yeung YS, Li WW, Chiang SW. The effects of indocyanine green and endoillumination on rabbit retina: an electroretinographic and histological study. Br J Ophthalmol 2005; 89: 897-900.

68 Maia M, Margalit E, Lakhanpal R, Tso MO, Grebe R, Torres $\mathrm{G}$ et al. Effects of intravitreal indocyanine green injection in rabbits. Retina 2004; 24: 69-79.

69 Sato Y, Tomita H, Sugano E, Isago H, Yoshida M, Tamai M. Evaluation of indocyanine green toxicity to rat retinas. Ophthalmologica 2006; 220: 153-158. 
70 Goldstein M, Zemel E, Loewenstein A, Perlman I. Retinal toxicity of indocyanine green in albino rabbits. Invest Ophthalmol Vis Sci 2006; 47: 2100-2107.

71 Chao AN, Chen SN, Kuo YH. Retinal function and histologic changes following intravitreal injection of indocyanine green in a rabbit model. J Ocul Pharmacol Ther 2004; 20: 450-459.

72 Enaida H, Sakamoto T, Hisatomi T, Goto Y, Ishibashi T. Morphological and functional damage of the retina caused by intravitreous indocyanine green in rat eyes. Graefes Arch Clin Exp Ophthalmol 2002; 240: 209-213.

73 Cekiç O, Morimoto T, Ohji M, Sawa M, Hasegawa T, Sakaguchi $\mathrm{H}$ et al. Nonaxoplasmic transfer of indocyanine green into the optic nerve after intravitreal application. Retina 2004; 24: 412-415.

74 Paques M. Nonaxoplasmic transfer of indocyanine green into the optic nerve after intravitreal application. Retina 2005; 25: 544; author reply 544-544; author reply 545.

75 Czajka MP, McCuen BW 2nd, Cummings TJ, Nguyen $\mathrm{H}$, Stinnett S, Wong F. Effects of indocyanine green on the retina and retinal pigment epithelium in a porcine model of retinal hole. Retina 2004; 24: 275-282.

76 Gandorfer A, Rohleder M, Charteris DG, Sethi C, Kampik A, Luthert P. Staining and peeling of the internal limiting membrane in the cat eye. Curr Eye Res 2005; 30: 977-987.

77 Saikia P, Maisch T, Kobuch K, Jackson TL, Baumler W, Szeimies RM et al. Safety testing of indocyanine green in an ex vivo porcine retina model. Invest Ophthalmol Vis Sci 2006; 47: 4998-5003.

78 Mennel S, Meyer CH, Tietjen A, Rodrigues EB, Schmidt JC. Patent blue: a novel vital dye in vitreoretinal surgery. Ophthalmologica 2006; 220: 190-193.

79 Sippy BD, Engelbrecht NE, Hubbard GB, Moriarty SE, Jiang S, Aaberg TMJ et al. Indocyanine green effect on cultured human retinal pigment epithelial cells: implication for macular hole surgery. Am J Ophthalmol 2001; 132: 433-435.

80 Murata M, Shimizu S, Horiuchi S, Sato S. The effect of indocyanine green on cultured retinal glial cells. Retina 2005; 25: 75-80.

81 Yam HF, Kwok AK, Chan KP, Lai TY, Chu KY, Lam DS et al. Effect of indocyanine green and illumination on gene expression in human retinal pigment epithelial cells. Invest Ophthalmol Vis Sci 2003; 44: 370-377.

82 Stalmans P, Van Aken EH, Veckeneer M, Feron EJ, Stalmans I. Toxic effect of indocyanine green on retinal pigment epithelium related to osmotic effects of the solvent. Am J Ophthalmol 2002; 134: 282-285.

83 Rezai KA, Farrokh-Siar L, Ernest JT, van Seventer GA. Indocyanine green induces apoptosis in human retinal pigment epithelial cells. Am J Ophthalmol 2004; 137: 931-933.

84 Jackson TL, Hillenkamp J, Knight BC, Zhang JJ, Thomas D, Stanford MR et al. Safety testing of indocyanine green and trypan blue using retinal pigment epithelium and glial cell cultures. Invest Ophthalmol Vis Sci 2004; 45: 2778-2785.

85 Hsu SL, Kao YH, Wu WC. Effect of indocyanine green on the growth and viability of cultured human retinal pigment epithelial cells. J Ocul Pharmacol Ther 2004; 20: 353-362.

86 Kunikata H, Tomita H, Abe T, Murata H, Sagara Y, Sato H et al. Hypothermia protects cultured human retinal pigment epithelial cells against indocyanine green toxicity. J Ocul Pharmacol Ther 2007; 23: 35-39.
87 Jin Y, Uchida S, Yanagi Y, Aihara M, Araie M. Neurotoxic effects of trypan blue on rat retinal ganglion cells. Exp Eye Res 2005; 81: 395-400.

88 Iriyama A, Uchida S, Yanagi $\mathrm{Y}$, Tamaki $\mathrm{Y}$, Inoue $\mathrm{Y}$, Matsuura $\mathrm{K}$ et al. Effects of indocyanine green on retinal ganglion cells. Invest Ophthalmol Vis Sci 2004; 45: 943-947.

89 Iriyama A, Yanagi Y, Uchida S, Tamaki Y, Aihara M, Obata $\mathrm{R}$ et al. Retinal nerve fibre layer damage after indocyanine green-assisted vitrectomy. Br J Ophthalmol 2004; 88: 1606-1607.

90 Ikagawa $\mathrm{H}$, Yoneda M, Iwaki M, Isogai Z, Tsujii K, Yamazaki $\mathrm{R}$ et al. Chemical toxicity of indocyanine green damages retinal pigment epithelium. Invest Ophthalmol Vis Sci 2005; 46: 2531-2539.

91 Burk SE, Da Mata AP, Snyder ME, Rosa RHJ, Foster RE. Indocyanine green-assisted peeling of the retinal internal limiting membrane. Ophthalmology 2000; 107: 2010-2014.

92 Gandorfer A, Messmer EM, Ulbig MW, Kampik A. Indocyanine green selectively stains the internal limiting membrane. Am J Ophthalmol 2001; 131: 387-388.

93 Gandorfer A, Haritoglou C, Gass CA, Ulbig MW, Kampik A. Indocyanine green-assisted peeling of the internal limiting membrane may cause retinal damage. $A m \mathrm{~J}$ Ophthalmol 2001; 132: 431-433.

94 Gandorfer A, Haritoglou C, Gandorfer A, Kampik A. Retinal damage from indocyanine green in experimental macular surgery. Invest Ophthalmol Vis Sci 2003; 44: 316-323.

95 Grisanti S, Szurman P, Gelisken F, Aisenbrey S, OficjalskaMlynczak J, Bartz-Schmidt KU. Histological findings in experimental macular surgery with indocyanine green. Invest Ophthalmol Vis Sci 2004; 45: 282-286.

96 La Heij EC, Dieudonne SC, Mooy CM, Diederen RM, Liem AT, van Suylen RJ et al. Immunohistochemical analysis of the internal limiting membrane peeled with infracyanine green. Am J Ophthalmol 2005; 140: 1123-1125.

97 Haritoglou C, Freyer W, Priglinger SG, Kampik A. Light absorbing properties of indocyanine green (ICG) in solution and after adsorption to the retinal surface: an ex-vivo approach. Graefes Arch Clin Exp Ophthalmol 2006; 244: 1196-1202.

98 Stalmans P, Feron EJ, Parys-Van Ginderdeuren R, Van Lommel A, Melles GR, Veckeneer M. Double vital staining using trypan blue and infracyanine green in macular pucker surgery. Br J Ophthalmol 2003; 87: 713-716.

99 Kolacny D, Parys-Vanginderdeuren R, Van Lommel A, Stalmans P. Vitrectomy with peeling of the inner limiting membrane for treating diabetic macular edema. Bull Soc Belge Ophtalmol 2005; 296: 15-23.

100 Lanzetta P, Polito A, Del Borrello M, Narayanan R, Shah VA, Frattolillo A et al. Idiopathic macular hole surgery with low-concentration infracyanine green-assisted peeling of the internal limiting membrane. Am J Ophthalmol 2006; 142: 771-776.

101 Van De Moere A, Stalmans P. Anatomical and visual outcome of macular hole surgery with infracyanine greenassisted peeling of the internal limiting membrane, endodrainage, and silicone oil tamponade. $A m \mathrm{~J}$ Ophthalmol 2003; 136: 879-887.

102 Ullern M, Dubreuil F, Nourry H, Poisson F, Baudouin C. [Macular hole surgery with and without infracyaninegreen-guided removal of the internal limiting membrane]. J Fr Ophtalmol 2007; 30: 53-57. 
103 Ullern M, Roman S, Dhalluin JF, Lozato P, Grillon S, Bellefqih $\mathrm{S}$ et al. [Contribution of intravitreal infracyanine green to macular hole and epimacular membrane surgery: preliminary study]. J Fr Ophtalmol 2002; 25: 915-920.

104 Rivett K, Kruger L, Radloff S. Infracyanine-assisted internal limiting membrane peeling in macular hole repair: does it make a difference? Graefes Arch Clin Exp Ophthalmol 2004; 242: 393-396.

105 Husson-Danan A, Glacet-Bernard A, Soubrane G, Coscas G. Clinical evaluation of the use of indocyanine green for peeling the internal limiting membrane in macular hole surgery. Graefes Arch Clin Exp Ophthalmol 2006; 244: 291-297.

106 Foulquier S, Glacet-Bernard A, Sterkers M, Soubrane G, Coscas G. [Study of internal limiting membrane peeling in stage-3 and -4 idiopathic macular hole surgery]. J Fr Ophtalmol 2002; 25: 1026-1031.

107 Garweg JG, Bergstein D, Windisch B, Koerner F, Halberstadt M. Recovery of visual field and acuity after removal of epiretinal and inner limiting membranes. $\mathrm{Br} \mathrm{J}$ Ophthalmol 2008; 92: 220-224.
108 Kiilgaard JF, Nissen $\mathrm{MH}$, la Cour M. An isotonic preparation of $1 \mathrm{mg} / \mathrm{ml}$ indocyanine green is not toxic to hyperconfluent ARPE19 cells, even after prolonged exposure. Acta Ophthalmol Scand 2006; 84: $42-46$.

109 Kodjikian L, Richter T, Halberstadt M, Beby F, Flueckiger F, Boehnke $\mathrm{M}$ et al. Toxic effects of indocyanine green, infracyanine green, and trypan blue on the human retinal pigmented epithelium. Graefes Arch Clin Exp Ophthalmol 2005; 243: 917-925.

110 Haritoglou C, Gandorfer A, Gass CA, Kampik A. Histology of the vitreoretinal interface after staining of the internal limiting membrane using glucose $5 \%$ diluted indocyanine and infracyanine green. Am J Ophthalmol 2004; 137: 345-348.

111 Dubreuil F, Ullern M, Lozato P, Rodrigues-Grillon S, Baudouin C. [Advantages of confocal microscopy in the analysis of epiretinal membranes and internal limiting membranes after macular surgery]. J Fr Ophtalmol 2005; 28: 19-29. 